\title{
Enterprise Merger of Human Resources Integration Problems Probing
}

\author{
Qian Ge, Haimin Cao \\ Shanghai University of Engineering Science, Shanghai, China \\ Email: 735434038@qq.com
}

Received 20 March 2014; revised 24 April 2014; accepted 2 May 2014

Copyright (C) 2014 by authors and Scientific Research Publishing Inc.

This work is licensed under the Creative Commons Attribution International License (CC BY). http://creativecommons.org/licenses/by/4.0/

cc) (i) Open Access

\begin{abstract}
Since the 20th century, enterprise merger frenzy has become a global trend, and merger of human resources integration is a crucial link. Acquisition is not only to the test of the system reform, but also of the enterprise culture inheritance, which carries forward the challenge. This paper will introduce human resource integration problems, based on the analysis of the present status of this international study, in the enterprise merger motivation and introduce the main items, on the basis of human resources in acquisition integration and the importance may face problems and solutions to carry on the analysis, based on the example analysis [1].
\end{abstract}

\section{Keywords}

Enterprise Merger, Human Resource Integration, Problems Facing, Countermeasures

\section{Introduction}

At the end of the 20th century, the integration of the world and economic globalization is more and more intense, the enterprise merger and acquisition has become a trend of globalization. Enterprises through mergers and acquisitions grow on their own, but most enterprise mergers and acquisitions are ultimately failed, which makes more and more enterprises gradually realize that $\mathrm{M} \& \mathrm{~A}$ is not only the recombination of financial and material resources, but also on the integration of human resources. It is particularly important to the integration of human resources, and the main purpose of enterprises is to make a profit, so as to obtain more markets, and it also provides strong guarantee for the implementation of enterprise merger and acquisition. 


\section{Research Status at Home and Abroad on the Integration of Human Resources in Enterprise Merger and Acquisition Research}

\subsection{Foreign Research Achievements on Human Resource Integration in Enterprise Merger and Acquisition}

Research progressed in this field abroad relatively quickly. The western developed countries mainly human resources integration of enterprise merger and acquisition from the perspective of various humanistic theory do more research. The following main research status abroad:

\subsubsection{The Research Results of Peter Drucker}

Management guru Peter Drucker wrote a classic "Frontiers of management”, he once in the book summarizes several principles, probably to have following five [2]:

First, to the success of mergers and acquisitions, $\mathrm{M} \& \mathrm{~A}$ can not only consider the acquirer can bring what benefit to themselves, the twenty should decide for themselves what can bring the benefits for $\mathrm{M} \& \mathrm{~A}$.

Second, the enterprise only a central core, must launch comprehensive business ideas and concepts.

Third, merger occurs later in a year, in order to revitalize the enterprise, the merger should provide important management personnel to the enterprise $\mathrm{M} \&$ A to help them.

Fourth, when the merger occurs later in a year, in order to enhance the performance of the company, it is particularly important to let two persons in enterprises of major adjustment position.

Fifth, when the company merged consumers, products, market to be respected, or mergers and acquisitions will not produce the effect.

\subsubsection{The Research Results of Alexandra Reid Rajkos}

He wrote a book "art" is the use of M \& A integration, question and answer, the post merger staff retention and board and etc.

\subsubsection{The Research Results of Xieweige and Walsh}

Walsh and Xieweige assessment conducted comment on human resources integration in mergers and acquisitions, and discusses the employees in $\mathrm{M} \&$ a tense occupation, ambiguity, action difficulty, productivity, consumption of financial security, work place reconfiguration, colleagues mutual trust issues such as the representative of the feelings [3].

\subsection{Domestic Research Achievements on Human Resource Integration in Enterprise Merger and Acquisition}

The integration of research on this problem in our country, after the development in the $\mathrm{M} \& \mathrm{~A}$ practice, the research of relative lack of further research, and after the $M \&$ A should be how to do the research of human resources integration scheme of enterprise $\mathrm{M} \& \mathrm{~A}$ technical maneuverability, more is insufficient. At present domestic research condition as follows:

\subsubsection{The Research Results of Luo Jinlian}

Luo Jinlian (Tongji University) from the view of improving group performance, puts forward the application of skills and Xiang Celve on the integration of human resources, human resources management rigidly adheres to the general enterprise is its disadvantages: contact management problems though and mergers and acquisitions in the integration of human resources, although has certain reference function, but is not suitable for.

\subsubsection{The Research Results of Wei River}

Wei Jiang wrote a book, is the "M \& A new thinking of core competence strategy of merger and integration management model based on the relative invariance", how to keep the human resources team this article simply expounds merger \& acquisition, reconstruction include psychological contract employee's and how to retain key talents etc. to do a simple narrative.

\subsubsection{The Research Results of Yanshimei}

She wrote "the strategic human resource management" such a book [4]. This has been very clear on the human 
resources management and the Inter Organizational Relationship restructuring in the book, but this book will be the integration of human resources issues in mergers and acquisitions as a minor problem to be studied, no deep systematic and theoretical requirements.

\section{The Reason of Enterprise Merger and the Main Stages and the Importance of Human Resource Integration}

\subsection{The Motivation of M \& A and the Main Stages}

The enterprise is a capital organization, it will chase the maximum capital appreciation, enterprises in order to pursue the biggest motivation for capital appreciation, try to complete the merger and acquisition of the investment activity is necessary, because the pressure of competition is also more important reason, but the merger of an enterprise itself, in the real world there will be different forms and different idea and purpose, the future planning of each enterprise are different, and their development is not like. Main items: the case of mergers and acquisitions usually proceed after merger, enterprise, started up from the understanding of the $\mathrm{M} \& \mathrm{~A}$ only a subconscious to truly implement to success generally have to go through the following stages [5]:

First, the preparation stage. Since the development of each enterprise is different, so the enterprise should according to their own situation develop your own strategy, formulate expectations for the target enterprise, the target enterprises need through comparing them, make several goals as an object, and then further to the goal enterprise financial, management, assets, personnel, tax, technology content is important to do further investigations to get the result.

Second, the merger and acquisition strategy design stage. Analysis in the first time that the process of data results, the finance and taxation, about the target enterprise merger and related payment, legal, financial and other relevant matters of the specific plan.

Third, contract negotiations stage in order to establish intent in $\mathrm{M} \& \mathrm{~A}$, after negotiations, to the acquisition plan as the basis, as the two negotiation basis, and then carrying out negotiation, according to the acquisition mode and price issues, signed the acquisition contract can.

Fourth, delivery and integration phase. When the two sides signed the contract after the merger, the next step is to make property rights delivery, then the integration of enterprise personnel, technology, business and so on, to consider the original of the merged enterprise to adapt to the situation and its own cultural background while the integration [6].

\subsection{The Importance of Human Resource Integration of Enterprise Merger}

In the human society has entered the era of knowledge economy in twenty-first Century, the first power as the enterprise development and factor is inevitable, the thought of human management has penetrated into enterprise management culture. Nowadays, the core competitiveness of enterprises is the human resource, this is an important point [7].

Regardless of the employees themselves or to the enterprise merger and acquisition is completed, six important events. With the merger and acquisition activity and development, personnel changes, the adjustment of organizational structure in always unavoidable, so that employees will be on the enterprise future development of doubt and uncertainty attitude, it will not produce the press and anxious psychology, change the negative emotions may make employees have the instinctive revolt attitude and self protection, which may cause the operation of enterprises affected by the downturn, production efficiency. The key point is that, after the founding of new enterprises, the trust is not very high, people may choose to give up the original post, these employees are mostly in the senior management staff, the result will make the human capital losses, these factors will produce bad results of M \& A, even the possible influence on the success or failure of M \& A produced.

In fact, human resource issues not related to an enterprise's internal matters, may also the relationship between the external situation of enterprises such as enterprises and vendors, customers, suppliers, if the enterprise staff's instability, enterprises will not be stable, this brought the loss is difficult to measure, and the management of most enterprises reality in may not be very well aware of this point.

Peter Drucker once described and analyzed five important factors in the success of M \& A [8], if mergers and acquisitions to succeed, then the key problem is the appointment and dismissal of executive. The Baum also proposed, an important reason of failure of $\mathrm{M} \& \mathrm{~A}$ is the lack of or no personnel involved in. As we all know, the market competition is very fierce competition, and the key in the market competition is the talent. Enterpris- 
es have the intangible asset and the key success factor is an advantage in human resources, especially has a number of outstanding talents. Who can get the best talent, who won an important weapon in the success, which occupies an advantageous position in the market competition. After the 90's of the twentieth Century, executives and outstanding technical staff plays a more and more important role in the enterprise, plays a vital role in. Many enterprises in order to retain outstanding talent, attract talent, continuously develop various attract way and generous treatment measures. However, if the enterprises in the merger and acquisition of enterprises after the other, the original plan and policy above is likely to adjust, and adjust the result is that the original outstanding talents of many outflow, so that $\mathrm{M} \& \mathrm{~A}$ a loss [9].

\section{Problems Which May Face in the Integration of Human Resources}

The process of human resource integration is so complicated. It may face so many problems and conflicts. The problems are about culture, employee and communication. The illustrations are as follows.

\subsection{Culture Conflict}

Culture is a complex concept, enterprise culture included in the belief, superstition, morality, value system and religious etiquette. They are the source of motivating people to the benefit and effect. A key factor in employee endeavours is an enterprise's core value system. Mergers and acquisitions failed, the main reason is that different culture is the difference. Whether mergers and acquisitions of domestic enterprises or Chinese enterprises transnational merger and acquisition, cultural difference is the main cause of enterprise merger and acquisition [10]. As there are great differences in culture and custom in our country, the domestic enterprises mergers and acquisitions are more likely to ignore the influence brought by cultural differences, so if you do not attach importance to this problem, will make the enterprise performance.

Overseas M \& A business enterprise of our country, the enterprise culture is gaining increasing attention, but also inevitably appear deviation. The cultural differences of different countries, and both the unification of cultural identity, also there are many different.

\subsection{Employee Pressure}

First of all, the staff do not know how will your future, the more confused. Majority of the M \& A case, the new organization with unknown big, employees do not understand their own will be located in what kind of status and role in the new organization, compensation and benefits will be what kind of adjustment, and the M \& A to the original commitment could really come true, this attitude will have a relatively large impact on the enterprise operation and development in the future.

Secondly, people more and more know to protect their own interests are not violated, so that employees are not good trust. The staff not only will not trust the new enterprises, the communication between each other will become no longer trust. Enterprises will be adjusted to do what, whether it will adopt what kind of method and measures, also is the adjustment to maintain their status of employees is the right to.

\subsection{The Lack of Effective Communication}

Regardless of which enterprises, the possibility of establishing a good key to effective communication determines the fate of the enterprise, in order to improve the performance of an enterprise, doing so will help employees can well involved in the organization's decision to. Because the enterprise lacks the more effective communication, the enterprise human resources cooperation difficult, high interlayer jockeying for position, the lack of trust between each other not good results.

\section{The Solutions to the Problems Facing Human Resources}

Facing the problems of human resources, we know the productive factors include many aspects. For this factors, different solutions are suggested.

\subsection{To Retain Key Talent}

The productive factors include many aspects, the most dynamic factor is the people, the staff support their ideas 
this is a normal phenomenon, so that the integration of human resources is the enterprise become more difficult. The key source of human resources integration problems faced of the enterprise is no special treatment to the integration of human resources, but and other capital to deal with, this ignores the problem of human resource integration in their subjective initiative, namely the person with initiative [11].

When after the merger of preparatory work, in order to make the human resource integration after $\mathrm{M} \& \mathrm{~A}$, should set up a task force to investigate the Target Corp, the full range of human resources situation, of course, according to the characteristics of their own businesses, especially the enterprise $\mathrm{M} \& \mathrm{~A}$ in fact, the judgment and analysis system thus, obtained a series of unity and strong science system, also is the human resources management system, the main contents of this system are: human resources salary management system unified, human resources incentive methods and human resources compensation system and so on, so as to avoid as much as possible human arbitrariness and blindness of resource integration.

Enterprises always hope to get employees for their hard work and loyalty, hope the staff to work hard to contribute their strength, however, in modern society, people's values have been changed thoroughly change thoroughly, in order to realize their value, the staff are very careful work, constantly in his occupation on the road more walk further, any enterprise cannot change this fact. This way an enterprise manager would argue that $\mathrm{M}$ \& A is to provide them with more and better prospects for development. At the same time, in order to retain talent of the enterprise, also can adopt the equity incentive measures. This policy can make the initiative of employees on real significance, the fate of the enterprises success and failure to relate in together, so that staff will take the initiative to request realizing short-term goals and strategic planning concern of enterprises, and actively participate in the management and decision-making of enterprises, creating value and benefits for the enterprise.

\subsection{Good Information and Psychological Communication}

\subsubsection{Communication before the M \& A with Staff}

Human resources department should be timely to the original company will be merged to make some explanations, adjust the employee attitude, and explain the merger will take what steps for the implementation of, so that it can be good for new enterprises, allowing employees to form a good sense of expectation. This reduces the prospects for the development of enterprise employees after the merger of uncertainty, thus can control staff effective flow.

\subsubsection{Communication during the M \& A with Staff}

The new M \& A a team, the most important task is to communicate with employees, understand their ideas and opinions, to reduce the friction between the organization and the staff, the staff and employees. Through a variety of measures timely publication of processing method's latest acquisition process and the key points to the employee, to avoid unnecessary misunderstanding.

\subsubsection{Communication after the M \& A with Staff}

The head of human resources at this stage to let each head of department and staff sincerely, adequate communication, so that they promptly into this new organization, feel the warmth of the collective, have no what feelings. At the same time, absolutely can't cover the unsolved problems, and shall timely solve various problems, and to tell the staff prepared, transition period after the merger will tell them for a period of time. At the same time also to do all kinds of feedback mechanism, understand their feelings in communication and feedback.

\subsection{Integration of New Corporate Culture}

For the enterprise's long-term business, plays a very important role in the enterprise culture, that is to say in the next ten years, can decide the success and failure of the enterprises or not. After the merger, the human resources department should be based on the M \& A of evaluation before merged enterprise culture type do, find the consistency and difference of two enterprises. The target enterprise staff belonging to the M \& A enterprise or business sense, identity comes from where, outside noting have is from the integration of enterprise culture and the. The enterprise culture is the enterprise in its continuous production and business activities in the formation of long-term accumulation, with the continuous development of enterprises, enterprise culture will follow the development together. The integration of specific practices are as follows: one is the culture of new enterprise culture, shaping a new enterprise culture requires that employees participate, so favorable to the new en- 
terprise culture execution is very useful; the two is the spread of a new corporate culture, through training, discussion, observation and other methods to allow employees to slowly come to accept new enterprise culture; three is the implementation of the new enterprise culture, establish a set of reference tracking inspection system, to ensure the implementation of new culture and carry out.

\subsection{To establish the Appropriate Incentive Policies}

\subsubsection{Combination of Material Incentive and Spirit Incentive}

The acquisition process should be the spiritual and material incentives combined to implement enterprise. In the development of the enterprise, must consider many factors, economic benefit is one of the important factors to consider, but not all. In the new environment, employees also need to consider many factors such as the work atmosphere, and the relationship between colleagues, new the development prospects of the company and the new work environment. But for a merger of companies, in order to stabilize the heart, must first give an incentive, in material and spirit incentive, of course, to put the two together well. Relevant data show that, in order to motivate the whole state, will increase $5 \%$ to $10 \%$ so that the transaction cost of the original, but doing so can realize merger this external trade strategy [12].

\subsubsection{Building a Shared Vision of Enterprise}

The human resource integration after $\mathrm{M} \& \mathrm{~A}$, personal and organizational well linked to pieces, enterprises in improving the overall performance and make personal achievement to enhance. Optimization of integration and coordination of the members of enterprises can will staff the focus together, at the same time, their interests are activated, create incentive and motivation, to complete the return expectations [13]. Due to the specific circumstances of different, enterprise human resources integration should choose measures and ideas, this will enhance the mutual cooperation between internal departments to further, enhance the ability to solve quality related problems, so as to achieve enterprise merger synergies to want.

\section{Conclusion}

Acquisition is not only the test of the system reform, but also of the enterprise culture inheritance which carries forward the challenge. More and more enterprises gradually realize that $\mathrm{M} \& \mathrm{~A}$ is not only the combination of financial and material resources, but also the integration of human resources. Enterprises should take rapid measures with problems faced during the process [14].

\section{References}

[1] Wang, F.Z. (2007) Issues and Problems of Human Resource Integration in Enterprise Acquisition. Anhui University School of Business and Management, Hefei, 100-150.

[2] Yang, J. (2005) Enterprise Merger Integration Research. Economic Management Press, Beijing, 10-19.

[3] Peter, D. (1988) Management Front. Economic Management Press, Beijing, 21-28.

[4] Liu, D.W. (2007) M \& A Research of Human Resources Integration. Chinese Economy Publishing House, 9-22.

[5] Ma, Y. (2005) M \& A Integration of Human Resources. Coal Economic Research Management, 4, 11-17.

[6] Lin, J. (2007) Mergers and Acquisitions in the Integration of Human Resources Performance Research. Southwestern University of Finance and Economics School of Business and Management, Chengdu, 20-33.

[7] Sun, S. (2007) How to Solve the Problem. Times Jinmao, Difficult Financing of SMEs in China, 5, 15-24.

[8] Kan, C. (2005) Against the Distortion of Accounting Information and the Reasons. Economist, 1, 10-14.

[9] Zhang, L. (2002) Integration Strategies of Human Resource Development of M \& A in Human Resources. 3-10.

[10] Peter, D. (2006) Management Practice. Mechanical Industry Press, Beijing, 55-62.

[11] Li, Y.Q. (2002) After Mergers and Acquisitions to Implement the Human Resources Development and Management. Human Resources in the Integration, 6, 23-29.

[12] Zhu, F. (2006) Reform and Management of 2006 Compensation Strategy. Enterprise Mergers and Acquisitions, 3, 6263.

[13] Tang, Q.L. (2005) M \& A Law Practice. People Publishing House, Beijing, 61-63.

[14] Wu, Y. (2005) The Human Resource Integration after M \& Strategy. Enterprise Vitality, 7, 3-4. 